\title{
CONFIGURAÇÕES E PROCESSOS RELACIONADOS À ESPACIALIDADE DE CENÁRIOS GEOMORFOLÓGICOS NO CONTEXTO DOS DEGRAUS ESCALONADOS DO SUDESTE DE
}

\author{
MINAS GERAIS - BRASIL
}

\section{Breno Ribeiro Marent*}

Universidade Federal de Minas Gerais

\section{Roberto Célio Valadão**}

Universidade Federal de Minas Gerais

\author{
Renata Jordan Henriques*** \\ Universidade Federal de Minas Gerais
}

Resumo: No sudeste de Minas Gerais é reconhecida a organização geomorfológica das principais bacias hidrográficas (Paraná, São Francisco, Doce e Paraíba do Sul) associadas a degraus escalonados. 0 contato entre esses degraus se estabelece através de escarpas, cujo contexto exibe, ainda, vales suspensos de diferentes dimensões e capturas fluviais. Essas capturas apresentam-se como indicador da evolução das bacias e ampliação dos degraus topográficos. 0 potencial erosivo das bacias situadas em posição inferior é evidenciado como elemento responsável por esses processos. Entretanto, diferentes mecanismos podem estar associados à evolução de escarpas e capturas fluviais. As análises realizadas neste trabalho se fundamentaram em duas escalas de abordagem: regional e local. A escala regional foi pautada no reconhecimento e espacialização de distintos cenários geomorfológicos. Para tal, os critérios estabelecidos foram a dimensão dos vales suspensos, posição do vale suspenso em relação à escarpa e condicionantes estruturais evidentes. A partir do reconhecimento dos diferentes cenários foram selecionados os mais representativos e, em escala local, mapeados seus componentes geomorfológicos de drenagem e relevo. As análises da configuração espacial de tais elementos evidenciaram importantes mecanismos com implicações para a evolução da área. Na organização geomorfológica geral da superfície os resultados notadamente indicam forte contribuição de condicionantes estruturais em escala local em detrimento daqueles manifestos em escala regional. A dimensão dos vales suspensos está relacionada à orientação de canais na borda das escarpas, estes organizados segundo controles estruturais locais. Os maiores vales tendem a apresentar drenagens perpendiculares ao avanço dos fluxos sobre a escarpa e, por consequência, facilitam a ocorrência de capturas em ponto de maior ordem hierárquica. Vales suspensos de menor dimensão podem estar relacionados à interceptação da drenagem em área de menor ordem hierárquica ou ao seccionamento do canal fluvial no mesmo sentido do fluxo remontante. Esse conjunto de elementos identificados converge para um quadro geomorfológico que assinala uma evolução condicionada por estruturas geológicas locais. Tais estruturas permitem a ocorrência de capturas fluviais segundo sua organização espacial de distintas dimensões espaciais e, em alguns casos, a configuração de novo cenário que sobrepõe um padrão estrutural mais recente sobre outro mais antigo após a incorporação da superfície altimetricamente superior a inferior.

Palavras-chave: Vale suspenso. Captura fluvial. Inflexão de drenagem. Controle estrutural.

\section{RELATED CONFIGURATIONS AND PROCESSES TO SPATIALITY OF THE GEOMORPHOLOGICAL SCENARIOS IN THE CONTEXT OF THE STAGGERED STEPS OF SOUTH-EAST MINAS GERAIS - BRAZIL}

Abstract: The south-east of Minas Gerais is recognized for its geomorphological organization of the main river basins (Paraná, São Francisco, Doce e Paraíba do Sul) associated with the in the form of staggered steps. The contact between these steps is established through escarpments, the context of which also shows hanging valleys of differing dimensions and river captures. These captures present as an indicator as to the evolution of the basins and the enlargement of the topographic steps. The erosive potential of the basins situated in inferior positions is shown as the component responsible for these processes. However, different mechanisms may be associated with the evolution of the escarpments and river captures. The analyses carried out in this study are based in two scales of approach: regional and local. The regional scale was based on recognition and spatialization of different geomorphological scenarios. For such, the established criteria were the size of the hanging valleys, position of the hanging valley in relation to the escarpment and evident structural conditioning. From the recognition of the different scenarios the most representative scenarios were selected and, on a local scale, its geomorphological drainage and relief components were mapped. The analysis of the spatial configuration of such elements evidenced important mechanisms with implications for the evolution of the area. Within the general geomorphological organization of the surface, the results are notable for indicating a strong contribution from local structural determinants as opposed to those

\footnotetext{
* Geógrafo e Doutor em Geografia pelo Departamento de Geografia da Universidade Federal de Minas Gerais. ORCID: https://orcid.org/0000-0001-6394-9908. E-mail: brenomarent@gmail.com.

** Geógrafo e Professor Doutor Titular do Programa de Pós-Graduação em Geografia da Universidade Federal de Minas Gerais. ORCID: https://orcid.org/0000-0003-34497628. E-mail: valadao@ufmg.br.

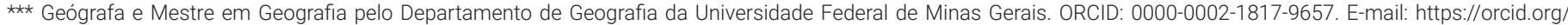
renatajhques@gmail.com
} 
manifested on a regional scale. The dimension of the hanging valleys is related to the orientation of the channels at the edges of the escarpments, these being organized according to local structural controls. The largest valleys tend to present drainage perpendicular to the advance of flow over the escarpment and, as a consequence, facilitate the occurrence of captures at a point of greater hierarchical order. Smaller hanging valleys may be related to the interception of drainage in an area of lower hierarchical order, or to the sectioning of the fluvial channel in the same direction as the flow of drainage headboards. This set of identified elements converge converge to a geomorphological framework that marks an evolution conditioned by local geological structures. Such structures allow the occurrence of river captures according to their spatial organization of different spatial dimensions and, in some cases, the configuration of a new scenario that overlaps a more recent structural pattern over an older one after incorporating the surface altimetrically higher than lower.

Keywords: Hanging valley. River captures. Drainage inflection. Structural control.

\section{CONFIGURATIONS ET PROCESSUS ASSOCIÉS À LA SPATIALITÉ DES SCÉNARIOS GÉOMORPHOLOGIQUES DANS LE CONTEXTE DES MARCHES TOPOGRAPHIQUES DANS LE SUD-EST DU MINAS GERAIS - BRÉSIL}

Résumé: L'organisation géomorphologique des principaux bassins versants du sud-est du Minas Gerais, au Brésil, est associée à des marches topographiques (Paraná, São Francisco, Doce et Paraíba do Sul). Le contact entre ces marches est établi à travers des escarpements, où les vallées suspendues de différentes dimensions et les captures fluviales sont courantes. Ces captures sont des indicateurs cohérents de l'évolution des bassins et de l'expansion des marches topographiques. Le potentiel d'érosion des bassins situés en position basse est mis en évidence comme un élément responsable de ces processus. Cependant, différents mécanismes peuvent être associés à l'évolution des escarpements et des captures fluviales. Les analyses réalisées dans ce travail reposaient sur deux échelles d’approche: régionale et locale. L'échelle régionale était basée sur la reconnaissance et la spatialisation de différents scénarios géomorphologiques. L'échelle régionale était basée sur la reconnaissance et la spatialisation de différents scénarios géomorphologiques, de sorte que les critères établis étaient la dimension des vallées suspendues, la position de la vallée suspendue par rapport à l'escarpement et les conditions structurelles. A partir de la reconnaissance des différents scénarios, les plus représentatifs ont été sélectionnés et, à l'échelle locale, leurs composantes géomorphologiques de drainage et de relief ont été cartographiées. L'analyse de la configuration spatiale de ces éléments a montré des mécanismes importants ayant des implications pour l'évolution de la région. Dans l'organisation géomorphologique générale de la surface, les résultats indiquent notamment une forte contribution des facteurs de conditionnement structurelles à l'échelle locale au détriment de celles qui se manifestent à l'échelle régionale. La dimension des vallées suspendues est liée à l'orientation des cours d'eau au bord des escarpements organisés selon les contrôles structurels locaux. Les plus grandes vallées ont tendance à avoir des drainages perpendiculaires à l'avancée des cours d'eau sur l'escarpement et, par conséquent, facilitent la survenue de captures à un point d'ordre hiérarchique supérieur. Les vallées suspendues plus petites peuvent être liées à l'interception du drainage dans une zone d'ordre hiérarchique inférieur ou à la coupe de cours d'eau dans le même sens que le flux en amont. Cet ensemble d'éléments identifiés converge vers un cadre géomorphologique qui signale une évolution conditionnée par des structures géologiques locales. Ces structures conduisent à l'installation des captures fluviales en fonction de leur organisation spatiale de différentes dimensions spatiales et, dans certains cas, la configuration d'un nouveau scénario qui chevauche un schéma structurel plus récent sur un plus ancien après l'incorporation de la surface altimétriquement supérieure à la surface inférieure.

Mots-clés: Vallée suspendue. Capture fluviale. Inflexion de drainage. Contrôle structurel.

\section{Introdução}

Em âmbito da organização geomorfológica regional, parte da porção sudeste do estado de Minas Gerais exibe rede de drenagem que se organiza compartimentada em nítida conformação com degraus topográficos escalonados, conforme apontado por Cherem et al. (2012, 2013) e Marent e Valadão (2015). Entre esses patamares ocorrem fronts escarpados que separam as principais bacias hidrográficas, sendo essas constituídas pelas bacias dos rios Paraná e São Francisco no degrau superior, bacia do rio Doce no degrau intermediário e bacia do rio Paraíba do Sul no degrau inferior. Cherem et al. (2012) e Salgado et al. (2012) verificaram através de taxas de denudação (10Be) que as bacias posicionadas em nível inferior estão se propagando em direção às bacias situadas em porção superior, através da erosão remontante mais intensa de suas cabeceiras situadas nas escarpas em relação ao planalto acima. Também reconheceram nessas porções algumas capturas fluviais como o principal processo na evolução do relevo e das bacias hidrográficas. Esses autores consideraram o nível de base como o condicionante que promove as capturas e a evolução das escarpas. Contudo, outros autores consideram, ainda, a heterogeneidade litoestrutural (GUNNELL; HARBOR, 2010; PRINCE et al. 2010) e a direção da drenagem (OLLIER, 2004; PRINCE et al. 2010) como fatores que podem influenciar nesses processos. Nesse sentido, as escarpas podem evoluir associadas a diversos mecanismos.

$\mathrm{Na}$ área de estudo, Salgado et al. (2012) e Cherem et al. (2013) não reconheceram controle litoestrutural que tenha influenciado a evolução quaternária dessas escarpas. Entretanto, Marent e Valadão (2015) identificaram condicionamento estrutural em diferentes escalas (regional e local) e controle litológico local que 
influenciam na evolução dos degraus. Esses autores reconheceram ainda a existência de vales suspensos ${ }^{1}$ por toda a borda das escarpas, alguns identificados como capturas por Cherem et al. (2013). Dessa forma, o objetivo deste trabalho foi realizar o mapeamento das bordas desses degraus mediante identificação dos diferentes cenários geomorfológicos nos quais estão inseridos os distintos divisores hidrográficos e sua relação ao maior ou menor recuo das escarpas e aos

1 Vale suspenso: vale cujo fundo encontra-se situado em nível superior à uma depressão adjacente, que pode ser outro vale, um lago, ou até mesmo o próprio mar (IBGE, 2004). No contexto geomorfológico deste trabalho, os vales suspensos marcam o registro do avanço dos cursos d'água em direção ao planalto localizado a montante. Logo, as áreas de drenagem nos planaltos estabelecidas a montante das escarpas e que drenam em direção às áreas mais rebaixadas foram consideradas como vales suspensos independente da dimensão que ocupam. seus mecanismos de evolução.

A área de estudo situa-se no sudeste do estado de Minas Gerais, entre os paralelos 20o 35' e $21035^{\prime} \mathrm{S}$ e meridianos 420 30' e 440 o 15' W (Figura 1). É representada pela bacia do alto rio Paraopeba (rio São Francisco), bacia do alto rio Grande (rio Paraná), bacia do rio Piranga/ alto rio Doce e bacia do rio Pomba (rio Paraíba do Sul). Os litotipos da área de estudo são aqueles formados em grande parte por complexos basais metamórficos, coberturas metassedimentares do Supergrupo Rio das Velhas e Grupo São João Del Rei e por uma diversidade de corpos intrusivos de composição litológica variada (ALKMIM, 2004).

Figura 1 - Localização da área de estudo.
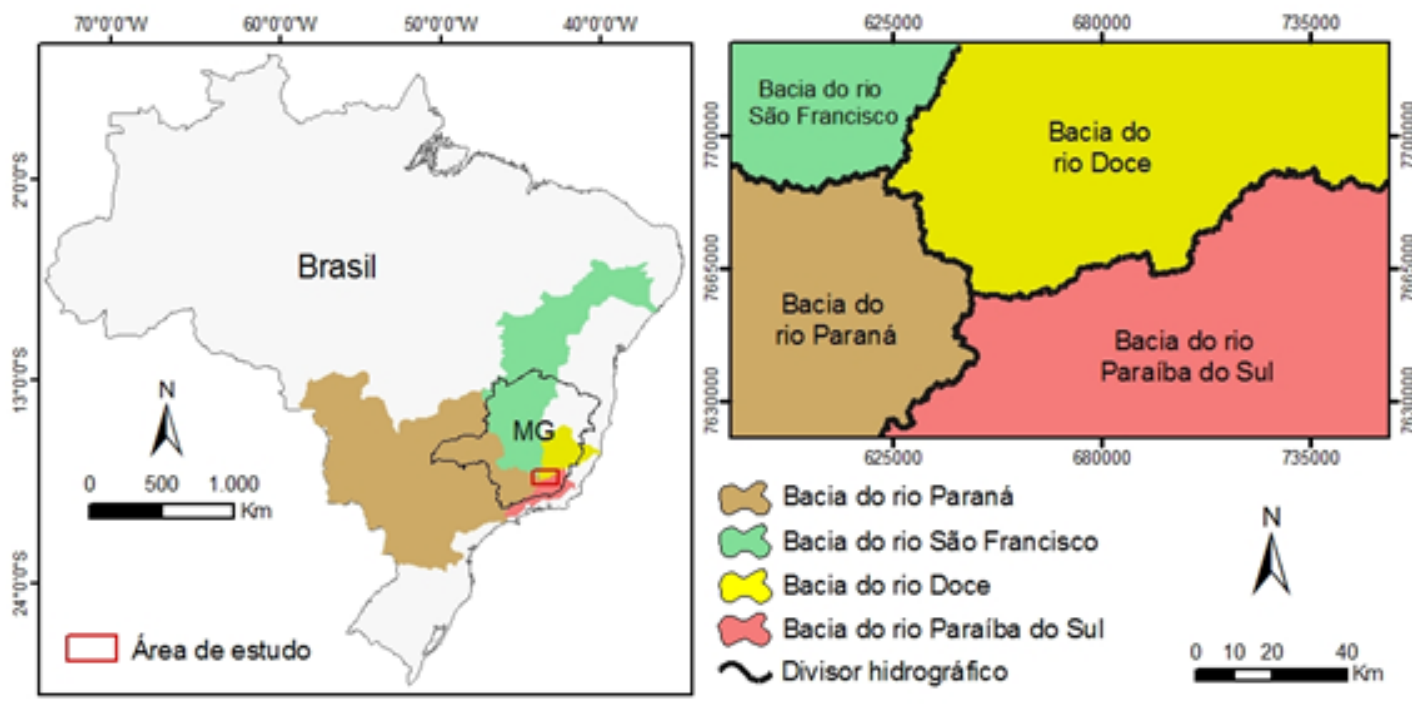

Fonte: Elaborado pelos autores.

\section{Materiais e métodos}

As investigações realizadas neste trabalho se fundamentaram em duas escalas de abordagem, uma regional e outra local. Em escala regional, os diferentes cenários geomorfológicos foram reconhecidos, classificados e espacializados, segundo sua representatividade e semelhança, baseado na: dimensão dos vales suspensos, posição do vale suspenso em relação à escarpa e condicionantes estruturais evidentes. A identificação inicial desses cenários foi realizada por meio de modelo de elevação digital (MDE), produzido a partir de imagens ASTER, com delimitação do divisor hidrográfico e escarpas. A partir do reconhecimento dos diferentes cenários, em escala regional, foram selecionados os mais representativos para análise em maior detalhe.

Em escala local, a partir das áreas selecionadas, os principais componentes espaciais da superfície foram reconhecidos através de cartas topográficas do IBGE, na escala 1:50.000, e imagens de satélite Google Earth Pro. Os componentes reconhecidos foram: drenagens, linhas de cumeada, knickpoints ${ }^{2}$, pontos cotados, depósitos aluviais correspondentes a planícies de inundação, escarpas, vales suspensos, afloramentos rochosos, cicatrizes de movimentos de massa, inflexões de drenagem, rupturas de relevo alinhadas e sedes municipais.

Em trabalho de campo procurou-se reconhecer os elementos cartografados e identificar novas feições não visualizadas na escala abordada, a exemplo de estreitamentos de canais de drenagens, afloramentos rochosos e knickpoints. A partir desse conjunto de dados levantados por investigação cartográfica e trabalhos de campo foram produzidos mapas dos diferentes

2 Knickpoint: ocorre quando o ponto de um curso fluvial é mais íngreme em relação ao ponto adjacente (BURBANK; ANDERSON, 2001). Silva et al. (2006) apontam, ainda, que essa feição pode ser identificada na paisagem como "degraus" de diferentes dimensões, ao longo do perfil longitudinal de um canal fluvial. 
cenários geomorfológicos e, posteriormente, realizada sua análise e interpretação. Tais cenários permitiram destacar elementos em planta, da drenagem e relevo, com implicações na evolução das escarpas relacionados aos distintos contextos geomorfológicos.

\section{Resultados e discussões}

Em escala regional, os cenários geomorfológicos foram mapeados e classificados, de forma preliminar, de acordo com os seguintes elementos (Tabela 1; Figura 2): (i) dimensão do vale suspenso; (ii) posição topográfica do vale em relação à escarpa e (iii) controle estrutural evidente da drenagem e do relevo, identificado no MDE por meio de feições lineares. Esses cenários foram agrupados em quatro tipos:

A - Vales suspensos médios a grandes, localizados acima das escarpas, no qual a paisagem apresenta controle estrutural evidente.

B - Vale suspenso grande, localizado entre escarpas, no qual a paisagem exibe controle estrutural evidente.

C - Vales suspensos grandes, localizados acima das escarpas, no qual não se percebe controle estrutural evidente.

D - Vales suspensos pequenos, localizados acima das escarpas, no qual não se identifica controle estrutural evidente.

Tabela 1 - Área dos vales suspensos utilizada como critério para sua classificação quanto à dimensão.

\begin{tabular}{cc}
\hline Vale suspenso & Área $\mathrm{Km}^{2}$ \\
\hline Pequeno & $<5$ \\
\hline Médio & 5 a 15 \\
\hline Grande & $>15$ \\
\hline \multicolumn{2}{c}{ Fonte: Elaborado pelos autores. }
\end{tabular}

Os vales suspensos constituíram o elemento de primeira grandeza no reconhecimento e classificação, uma vez que representam a feição geomorfológica mais evidente da evolução das escarpas. Dentro dessa lógica foram selecionadas áreas mais representativas, na escala regional, que expressassem a diversidade de cenários encontrados, para a análise em escala de maior detalhe (Figura 2): cenário $A=>$ área 1 , cenário $B=>$ área 2 , cenário $C=>$ área 3 e cenário $D=>$ área 4 .

Figura 2 - Localização dos cenários geomorfológicos e das áreas analisadas em detalhe. As letras A, B, C e D referem-se aos quatro tipos de cenários geomorfológicos

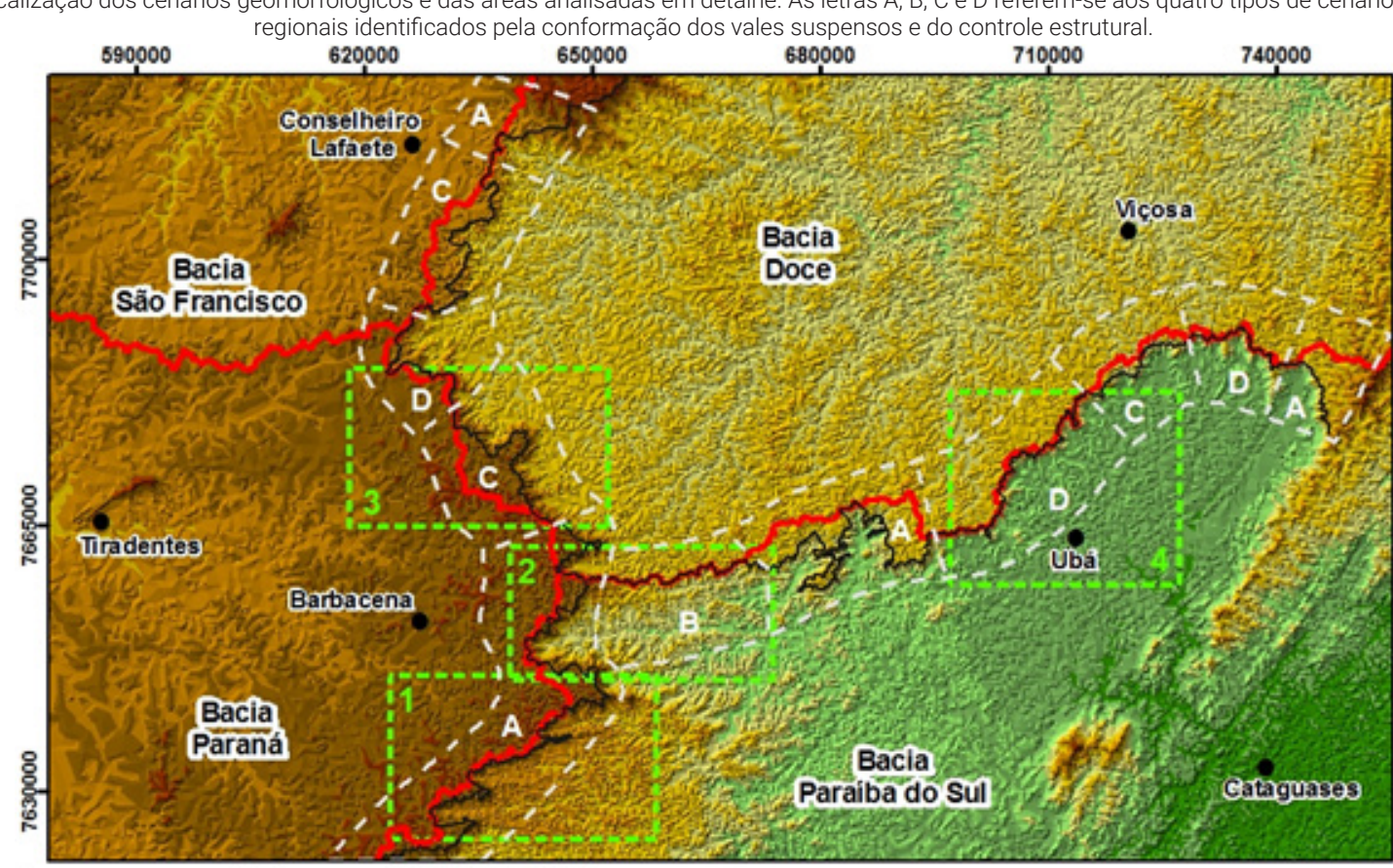

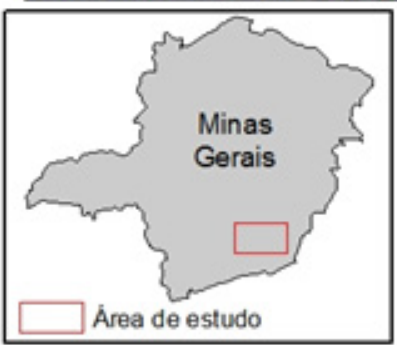

\section{Elevação (m)}

$1200-1520$

$1050-1200$

$900-1050$

$750-900$

$600-750$

$450-600$

$300-450$

$140-300$

Fonte: Elaborado pelos autores.

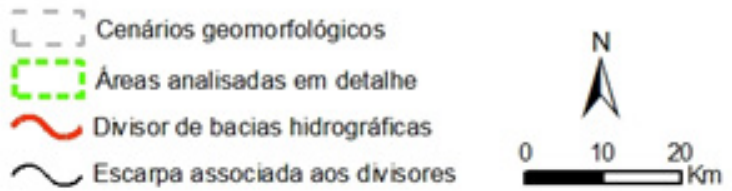

- Sede de município 
Área 1

A área 1 abrange trechos tanto da bacia do rio Paraná como da bacia do rio Paraíba do Sul (Figura 2). É representativa de cenário geomorfológico caracterizado por vales suspensos médios a grandes, localizados a montante da escarpa, no qual a paisagem exibe controle estrutural evidente sobre à conformação da drenagem e do relevo. Essa porção da bacia do rio Paraíba do Sul encontra-se em cotas altimétricas semelhantes às da bacia do rio Doce, sugestiva de correspondência de paleosuperfície regional abrangendo as duas bacias costeiras - Doce e Paraíba do Sul.

A análise em detalhe revela, na bacia do rio Paraná, drenagem e relevo orientados a NW-SE que sugerem, localmente, controle estrutural nessa direção (Figura 3). Feições assemelhando-se a inflexões de drenagem indicam caráter estrutural secundário NE-SW. Na bacia do rio Paraíba do Sul, a drenagem e o relevo exibem direção
E-W a ENE-WSW que denota controle estrutural local nessa direção. Feições assemelhando-se a inflexões de drenagem sugerem caráter estrutural secundário NESW e NW-SE. A organização geomorfológica na bacia do rio Paraíba do Sul assemelha-se à estruturação pré-cambriana mapeada por Brandalise (1991). Essa estruturação é composta por dobras antiformais e sinformais orientadas E-W a ENE-WSW, envolvidas por zonas de cisalhamento contracionais NE-SW que tendem a acompanhar porções do traçado da escarpa. Segundo Brandalise (1991), o interior dessa zona de cisalhamento compreende faixa de rochas gnáissicas enderbíticas e charnocktícas, da Suíte São Bento dos Torres, nas quais foram identificados alguns afloramentos. Um desses está associado a estreitamento de canal com estrangulamento de drenagem e knickpoint no ribeirão Patrimônio dos Padres, entre dois afloramentos rochosos, a montante de três inflexões de drenagem alinhadas e paralelas.

Figura 3 - Cenário geomorfológico correspondente a área 1

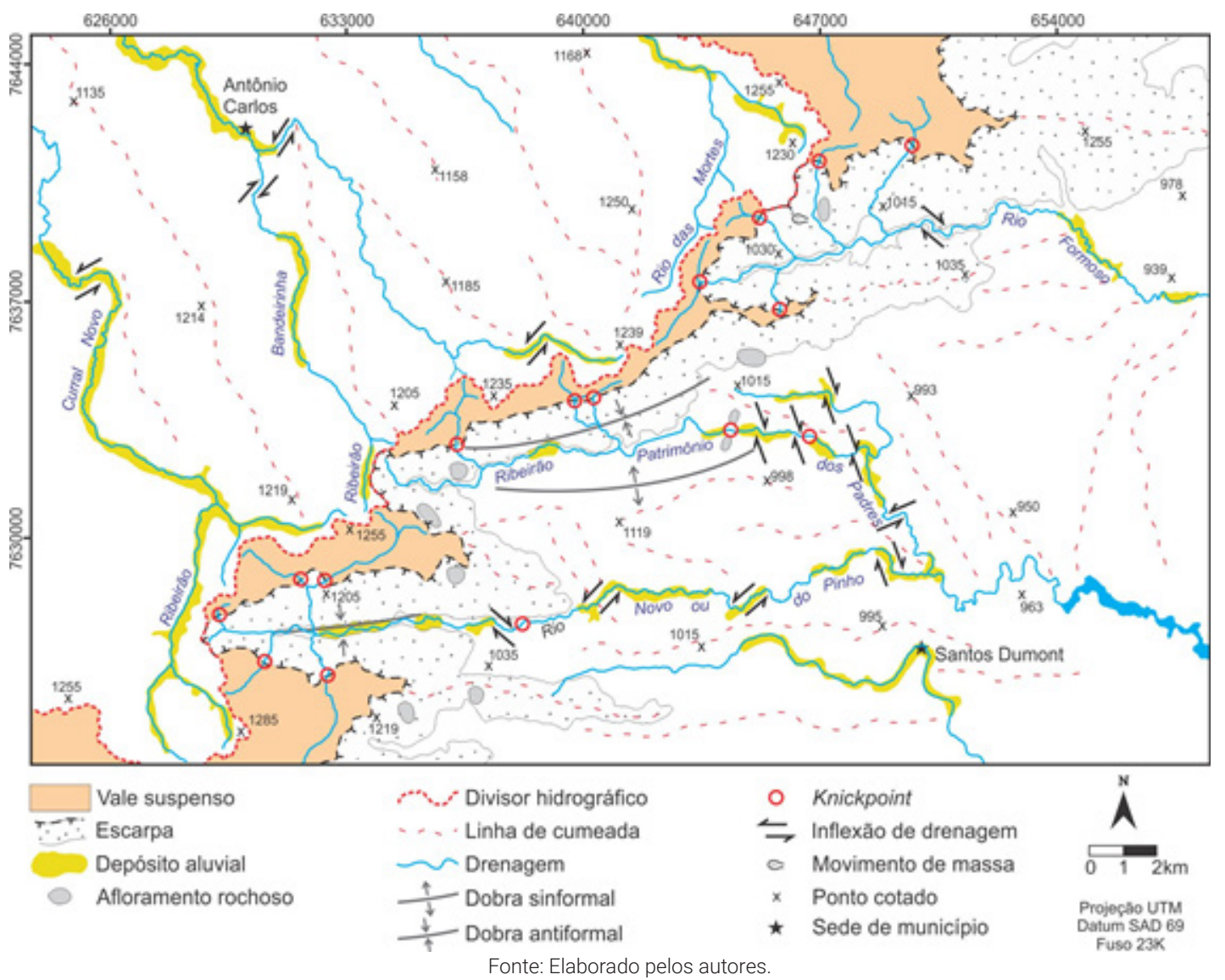

A análise da drenagem na bacia do rio Paraíba do Sul indica avanço em direção à bacia do rio Paraná, resultando em vales encaixados circundados por vales suspensos e elevada sinuosidade da escarpa (Figura 3). Na bacia do Paraíba do Sul, a montante da escarpa, inflexões bruscas de canais (tipo cotovelos) próximos a knickpoints dos vales suspensos apontam para um cenário de capturas fluviais. Corrobora para esse contexto a presença de acumulações aluviais desproporcionais para a configuração de borda de escarpa na bacia do Paraná, que podem chegar a mais 100 metros de largura, em áreas de cabeceiras de drenagem. Entretanto, nessa 
área, até o momento, não existe nenhum trabalho que relacione esses vales suspensos à temática das capturas fluviais.

As drenagens que esculpem o degrau superior apresentam-se, em geral, perpendiculares em relação aos canais que avançam pela escarpa do degrau inferior (Figura 3). Tal arranjo dos canais mostra que o avanço da drenagem sobre o degrau superior gerou vales suspensos de diferentes dimensões, a depender de onde o curso d'água foi seccionado. Nesse contexto, canais no degrau superior de direção perpendicular em relação à drenagem remontante têm maior propensão a originar vales suspensos maiores.

Dessa forma, o avanço dos cursos d'água sobre o degrau superior impõe uma reorganização da hidrografia que passa a ser submetida ao condicionamento estrutural do degrau inferior (Figura 3). Essa nova organização produz novo cenário que parece sobrepor um padrão estrutural mais recente sobre outro mais antigo. Feições tipo inflexões de drenagem, em ambos os degraus, também indicam o registro desse condicionamento estrutural que foi superposto. No degrau inferior, algumas dessas inflexões foram identificadas a montante de knickpoints que, por sua vez, foram reconhecidos em campo associados a estrangulamentos de drenagem no rio Novo e ribeirão Patrimônio dos Padres.

Área 2

A área 2 está localizada no setor dos divisores comuns às bacias do rio Paraná, Doce e Paraíba do Sul (Figura 2). É representativa do cenário geomorfológico caracterizado por vale suspenso grande, no qual a paisagem exibe controle estrutural evidente da drenagem e do relevo.

Nessa área, a análise em detalhe revela a presença de vales suspensos correspondentes aos três degraus topográficos: vale suspenso 1 - degrau inferior, vale suspenso 2 - degrau intermediário e vale suspenso 3 - degrau superior (Figuras 3, 4 e 5). 0 vale suspenso 1, representativo de tal região, está inserido no Degrau Paraíba do Sul (degrau inferior) e encontra-se em cotas inferiores aos degraus Doce (degrau intermediário) e Paraná-São Francisco (degrau superior), bem como em relação aos seus respectivos vales suspensos, 2 a NE e 3 a oeste. Sua localização em cotas inferiores aos degraus Doce e Paraná-São Francisco sugere um canal mais ajustado ao novo nível de base da bacia do rio Paraíba do Sul, porém ainda suspenso em relação ao rio Pomba.

Figura 4 - Cenário geomorfológico correspondente a área 2

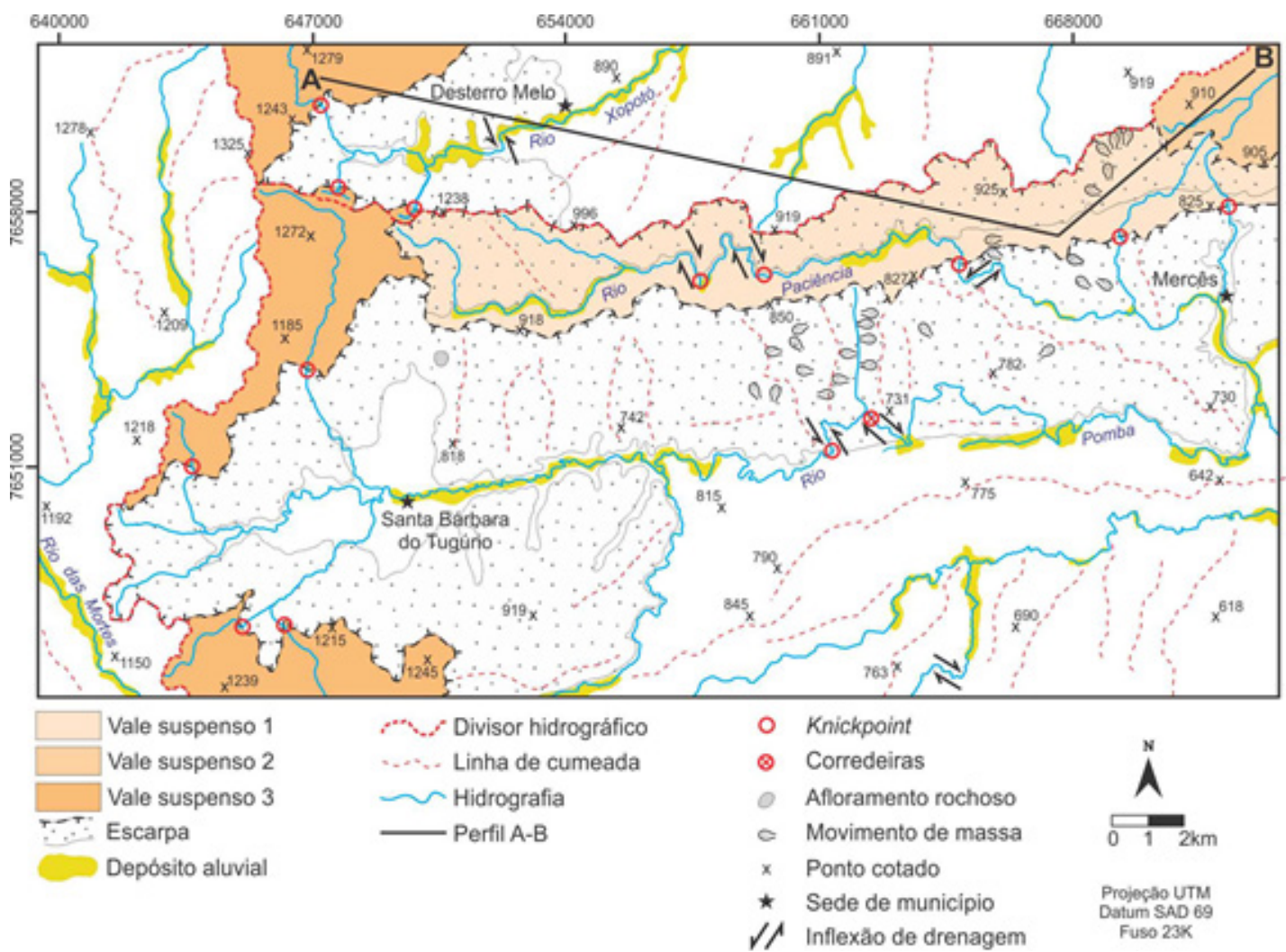

Fonte: Elaborado pelos autores. 
Figura 5 - Perfil topográfico que exibe os três vales suspensos situados nos distintos degraus topográficos localizados na Figura 4

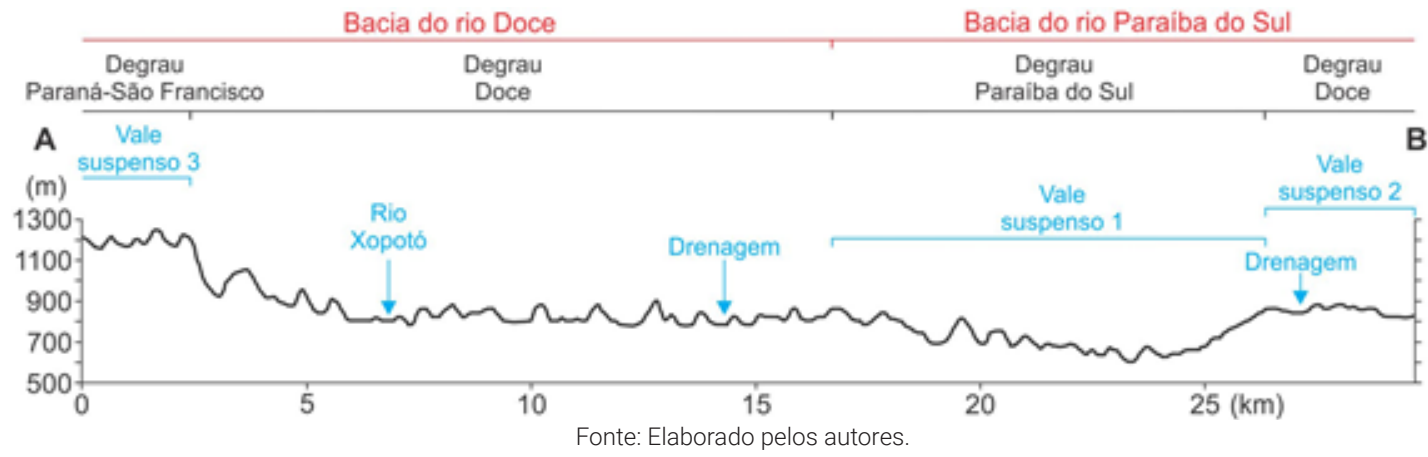

Na bacia do rio Paraíba do Sul, a porção analisada exibe drenagem e relevo orientados preferencialmente na direção E-W a ENE-WSW, o que indica controle estrutural nessa direção contrastante com as direções nas bacias adjacentes (Figura 4). Feições assemelhandose a inflexões de drenagem assinalam controle estrutural secundário NW-SE e NE-SW e parecem ter semelhança com a direção dos canais e do relevo das bacias adjacentes. Para esta mesma área, Brandalise (1991) mapeou fraturas condicionando a porção oeste do trecho do rio Pomba, enquanto Brandalise e Viana (1993) reconheceram falhas na porção leste dos rios Pomba e Paciência, assinalando nítida correspondência entre a organização geomorfológica e a estrutural. 0 vale encaixado a oeste, circundado por vales suspensos, com elevada sinuosidade da escarpa, sugere maior avanço da rede hidrográfica nesse sentido e coincide com a direção estrutural principal. 0 avanço da rede de drenagem sobre os degraus situados acima impõe a reorganização da hidrografia, que passa a ser submetida a novo condicionamento estrutural do degrau inferior. 0 controle estrutural local parece direcionar a evolução da bacia orientando o avanço da drenagem mais sobre a bacia do rio Paraná do que em relação à do rio Doce, com implicações para o ganho e perda de área entre elas.

No rio Paciência, fora do contexto das bordas de escarpadas mais elevadas, knickpoints encontramse associados a feições de estreitamentos bruscos e inflexões de drenagem (Figura 4). No rio Pomba, essas feições de inflexões de drenagem encontramse associadas a knickpoint e corredeira. Entretanto, os knickpoints do rio Pomba e das bordas escarpadas não foram identificados em campo como os demais, mas apenas por imagem de satélite.

Cicatrizes de movimentos de massa, algumas configurando canais incisos tipo voçoroca, ocorrem na porção central da área analisada (Figura 4). Podem ser agrupadas de forma preliminar a três condições: (i) localizadas em cabeceiras de canais de primeira ordem; (ii) relacionadas à erosão fluvial pelo solapamento das margens do canal; e (iii) sem conexão aparente com a dinâmica fluvial. Essas cicatrizes exibem concentração incomum na área e nas proximidades de trechos em que ocorre interseção de feições do tipo inflexões de drenagem indicando agrupamento de estruturas nessa localidade. Isso pode significar a atuação de estruturas, influência de tectônica ativa ou mesmo ocorrência de litologias mais friáveis. Entretanto, no mapeamento geológico existente para a área (BRANDALISE; VIANA, 1993) - escala 1:100.000 - não existem estruturas reconhecidas que possam estar associadas às inflexões de drenagem e a litologia que predomina são ortognaisses do Complexo Mantiqueira.

\section{Área 3}

A área 3 está localizada entre os divisores das bacias dos rios Paraná e Doce (Figura 2). É representativa do cenário geomorfológico caracterizado pela ocorrência de um vale suspenso de grande porte, localizado a montante da escarpa, no qual na escala regional não se percebe controle estrutural evidente da drenagem e do relevo.

A análise em detalhe da área revela, em sua porção central, relevo e drenagens orientados a NW-SE, enquanto em suas extremidades SW e NE estão orientadas a NESW (Figura 6). Brandalise (1991) mapeou, em escala de maior detalhe (1:100.000), na porção central desta área um conjunto de falhas de direção NW-SE que se encontra sobre o vale suspenso e adjacências, enquanto na porção SW a direção predominante é NE-SW. Na escarpa foram verificados, através de imagens de satélite, rupturas de declive alinhadas assumindo a direção NW-SE. Feições assemelhando-se a inflexões de drenagem ocorrem acima e abaixo da escarpa na direção NW-SE e NE-SW. Esse conjunto de elementos denota, portanto, controle estrutural NW-SE e NE-SW dessa área e que orienta tanto a drenagem como o relevo. 
Figura 6 - Cenário geomorfológico correspondente a área 3

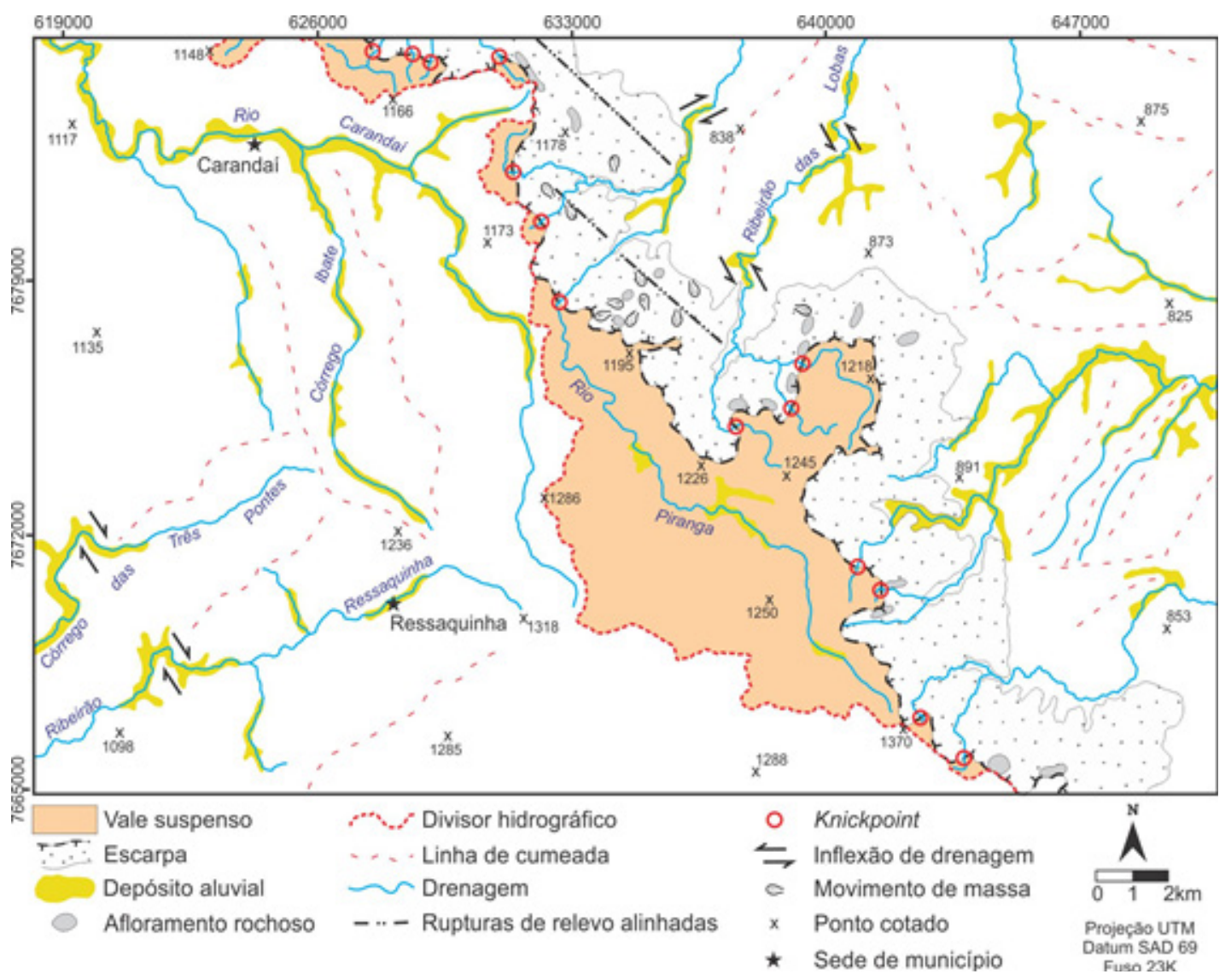

Fonte: Elaborado pelos autores.

0 grande vale suspenso que ocorre na área (Figura 6) indica ter relação com as estruturas mapeadas por Brandalise (1991), uma vez que se apresenta orientado segundo essas. Esse vale suspenso foi identificado por Salgado et al. (2012) e Cherem et al. (2013) como proveniente de captura fluvial, sendo encontrado registro sedimentar em vale seco como comprovação desse evento. As estruturas e drenagens no vale suspenso, por sua vez, apresentam orientação discordante dos canais que avançam pela escarpa. Isso demonstra que a hidrografia, com controle estrutural perpendicular aos cursos d'água que se localizam na escarpa, pode gerar grandes capturas a depender do ponto onde é seccionada.

Cicatrizes de movimentos de massa concentram-se de forma incomum próximo a uma das rupturas de declive quando comparada a outras porções dessa escarpa (Figura 6), uma vez que na área a litologia predominante é a mesma e as declividades são semelhantes, sendo composta por diorito a quartzodiorito e tonalito (BRANDALISE, 1991). Essas cicatrizes aparentemente encontram-se dissociadas de processos da dinâmica fluvial. Por sua vez, a ruptura de relevo localizada mais a norte encontra-se sem a presença de movimentos de massa, embora a montante dessa ruptura ocorram afloramentos rochosos que se distribuem ao longo de quase toda a borda da escarpa exibindo depósitos de tálus.

Área 4

A área 4 está localizada entre os divisores das bacias dos rios Doce e Paraíba do Sul (Figura 2). É representativa de cenário geomorfológico caracterizado por pequenos vales suspensos, localizados acima da escarpa, no qual na escala regional não se percebe controle estrutural evidente da drenagem e do relevo.

A análise em detalhe da área revela na bacia do rio Doce o relevo e a drenagem orientados na direção NW-SE, enquanto feições tipo inflexão de drenagem apresentam direção NE-SW (Figura 7). Próximo ao divisor e à borda da escarpa são encontradas, ainda, acumulações aluviais que podem chegar a mais 100 metros de largura. A bacia do rio Paraíba do Sul exibe significativa concentração de depósitos aluviais em relação às demais áreas investigadas. Nessa bacia, a drenagem e o relevo indicam três direções: NW-SE, NE-SW e N-S. A direção NW-SE predomina em toda porção da bacia do rio Paraíba do Sul, a orientação NE-SW está a SE de Ubá na faixa compreendida pelo Complexo Juiz de Fora 
(NOCE et al., 2003) e a direção N-S a NE de Ubá. Feições tipo inflexão de drenagem e rupturas de relevo assumem direção predominante NE-SW, podendo chegar a NNESSW e ENE-WSW. Nessa área, o condicionamento dos elementos geomorfológicos a NE-SW e NW-SE indicam ser essas direções dominantes do controle estrutural local, com a drenagem assumindo direção preferencial NW-SE.

Figura 7 - Cenário geomorfológico correspondente a área 4

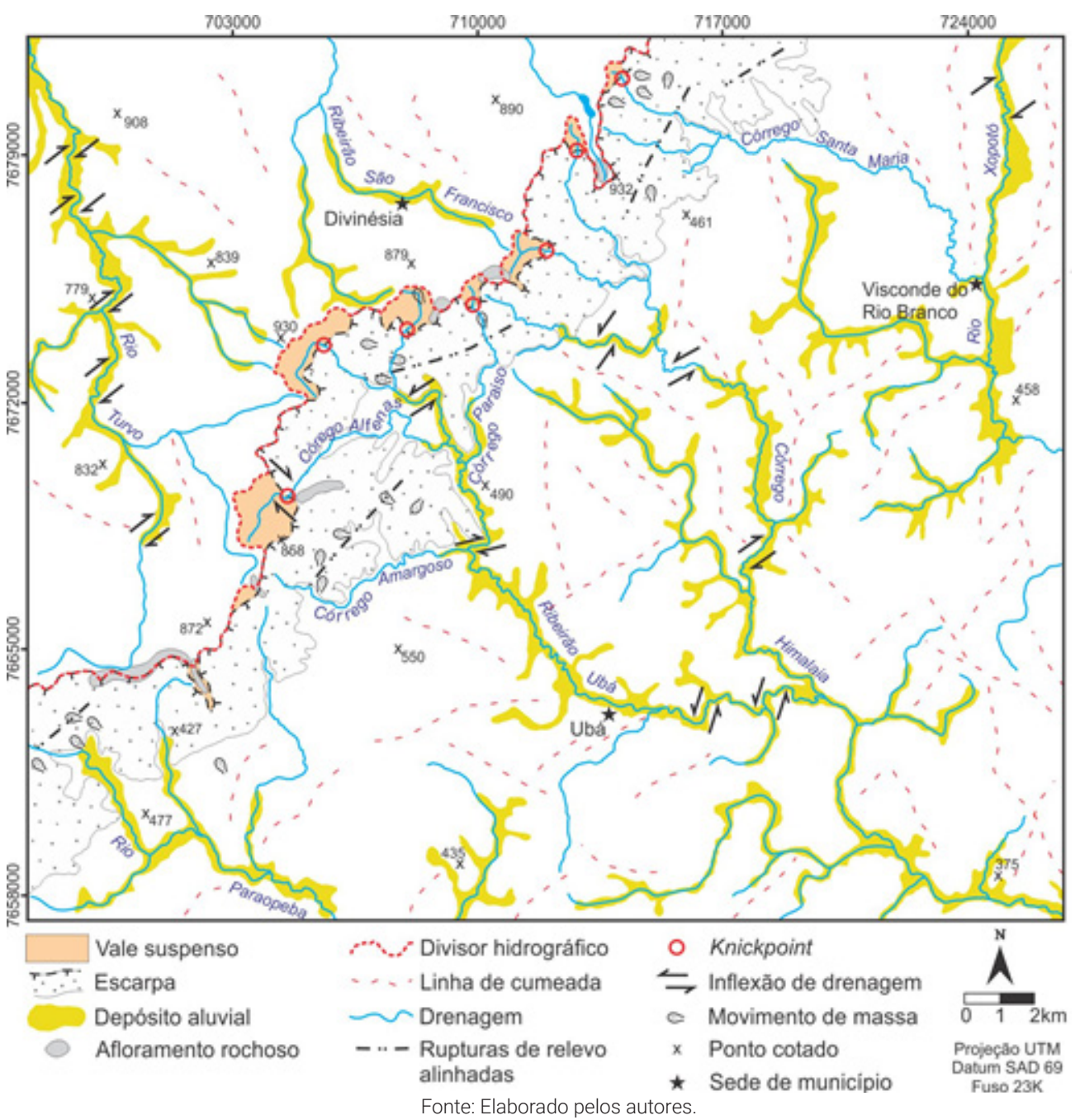

É possível que a dimensão dos vales suspensos tenha alguma relação com a direção da rede hidrográfica, com a drenagem de ambas as bacias orientadas preferencialmente a NW-SE, próximo à escarpa (Figura 7). A erosão remontante sugere capturas fluviais de pequena dimensão ou mesmo beheading - decapitação (BISHOP, 1995) -, uma vez que as drenagens das bacias tendem a apresentar a mesma direção predominante. Entretanto, o controle estrutural secundário pode prevalecer em algumas circunstâncias, como no córrego Alfenas que exibe direção NE-SW quase já totalmente incorporado ao degrau inferior. Esse canal mostra knickpoint associado à feição tipo estrangulamento de drenagem e do vale.

Cicatrizes de movimentos de massa, algumas configurando canais incisos tipo voçoroca, ocorrem ao longo da escarpa (Figura 7). Essas cicatrizes tendem a se concentrar próximas a rupturas de relevo alinhadas, o que pode significar uma gênese associada a movimentação de falhas não mapeadas na escala investigada e responsáveis pela desestabilização das vertentes. Cicatrizes menores associadas a terracetes também são encontradas nessa porção, porém não puderam ser mapeadas devido a sua pequena expressão espacial. Afloramentos rochosos se distribuem ao longo da escarpa apresentando foliação com caimento a SE nos ortognaisses e feições incipientes tipo pães de açúcar nos granitos, metasienitos alcalinos e enderbitos (BRANDALISE; VIANA, 1993).

\section{Aspectos gerais dos cenários geomorfológicos}

Ao longo das escarpas dos degraus escalonados do sudeste de Minas Gerais uma das feições morfológicas mais marcantes são os vales suspensos, que podem ser 
agrupados em diferentes cenários geomorfológicos, de acordo com sua dimensão e características espaciais. Alguns dos maiores vales nas bordas dos divisores hidrográficos São Francisco - Doce, Paraná - Doce e Doce - Paraíba do Sul foram investigados por Salgado et al. (2012) e Cherem et al. (2013), sendo constatadas evidências de captura fluvial. Evidências indiretas também são identificadas no mapeamento em detalhe dos cenários aqui apresentados. Tais cenários exibem vales suspensos com inflexões bruscas na rede de drenagem em forma de cotovelos a montante da ocorrência de knickpoints em típico padrão barbed. $\mathrm{Na}$ bacia adjacente evidenciam a presença de amplos vales fluviais, desproporcionais para o contexto de cabeceiras de drenagem em borda de escarpa, que podem chegar a mais de 100 metros de largura. 0 padrão barbed, segundo Howard (1967), é um dos indicadores de pirataria de drenagem. De acordo com Bishop (1995), nesse tipo de contexto a rede de drenagem é caracterizada por muitos cotovelos de captura, ou seja, confluências de tributários com ângulos próximos a $90^{\circ}$. $\mathrm{Na}$ área de estudo, os cursos d'água nos vales suspensos exibem direções sugestivas de antigas conexões com a hidrografia da bacia adjacente. Esses dados apontam para um cenário regional generalizado de capturas fluviais nas bordas das escarpas. Conforme Cherem et al. (2013) essas capturas fluviais encontram-se em diferentes estágios de desenvolvimento.

A evolução regional da área é marcada pela presença de vales suspensos que se apresentam como registro morfológico do avanço da drenagem sobre as bordas escarpadas. Esse avanço foi quantificado por Cherem et al. (2012) e Salgado et al. (2012) utilizando o isótopo cosmogênico ${ }^{10} \mathrm{Be}$. Em algumas áreas tais vales suspensos são cortados por vales encaixados com evidente condicionamento do relevo e da drenagem e que produzem elevada sinuosidade ao longo da escarpa. Em outras, apesar desse condicionamento não evidente na escala regional, o que se percebe em maior detalhe são orientações do relevo e da drenagem segundo direções estruturais muito bem marcadas. Essas por vezes assumem direções discordantes da orientação principal regional (NE-SW) como verificado por Marent e Valadão (2015). Tais elementos indicam que o controle em escala local pode se sobrepor ao regional na organização geomorfológica.

A dimensão dos vales suspensos parece estar relacionada à orientação dos canais na borda das escarpas. Os maiores vales suspensos tendem a apresentar drenagem perpendicular ao avanço dos fluxos d'água sobre a escarpa. Essas drenagens se encontram organizadas segundo direções preferenciais que evidenciam o controle estrutural em escala local. Segundo Prince et al. (2010) drenagens ortogonais ao fluxo remontante, frequentemente, mostram-se associadas a controle estrutural. Tal configuração permite capturas fluviais em ponto de elevada ordem hierárquica dos canais de drenagem localizados em morfologia de planalto (OLLIER, 2004; PRINCE et al., 2010), o que facilita a rápida dissecação pelo aumento de energia no fluxo da bacia capturada (PRINCE et al., 2010). Por sua vez, vales suspensos de pequena dimensão podem estar relacionados à interceptação da drenagem em ponto de pequena ordem hierárquica ou ao seccionamento do canal fluvial no mesmo sentido do fluxo remontante. Tal fato, em bordas escarpadas, implica na tendência de drenagens perpendiculares ao fluxo remontante exibirem capturas maiores e, consequentemente, serem submetidas à denudação mais rápida que leva ao maior recuo da escarpa num espaço de tempo menor.

Feições tipo inflexão de drenagem podem ser identificadas em todas as áreas. Algumas dessas inflexões de drenagem ocorrem associadas a estrangulamento de canais e knickpoints. De acordo com Howard (1967), estreitamento de vales ou canais podem indicar estruturas locais. Silva et al. (1993) no médio vale do rio Paraíba do Sul também encontraram estrangulamentos de canais associados a knickpoints. A coincidência de algumas dessas feições associadas contribui para um quadro sugestivo de atividade tectônica recente na área, uma vez que autores como Gontijo (1999), Modenesi-Gauttieri et al. (2002) e Silva et al. (2006) associaram a formação de knickpoints e inflexões de drenagem a movimentações tectônicas.

Cicatrizes de movimentos de massa ocorrem na maior parte das áreas investigadas, em geral associadas a rupturas de relevo alinhadas ou feições que se assemelham a inflexões de drenagem. Algumas dessas cicatrizes parecem se misturar a canais incisos do tipo voçoroca. Entre esses movimentos de massa, parte parece estar relacionada à dinâmica fluvial que erode as margens dos cursos d'água e desestabiliza as encostas, enquanto outros associados a cabeceiras de drenagem. Nesse sentido, Avelar e Coelho Netto (1992) e Coelho Netto (2003), no médio vale do Paraíba do Sul, identificaram em cabeceiras de drenagem fraturas ou intersecção dessas condicionando movimentos de massa e a evolução de vales. Por sua vez, uma parcela dos movimentos de massa parece estar dissociada de processos relacionados à dinâmica fluvial. Esses movimentos frequentemente aparecem associados a rupturas de relevo alinhadas e, em menor proporção, a anomalias de drenagem que se assemelham a inflexões de drenagem. 
Por fim, nota-se que a superfície altimétrica superior ao ser incorporada pela inferior passa a responder a novo condicionamento estrutural que se superimpõe sobre a nova superfície anexada. Tal fato decorre do avanço dos cursos d'água na forma de capturas fluviais que tem a capacidade de rejuvenescer e reorganizar a paisagem. Nesse sentido, a configuração estrutural da área sobre a qual a drenagem se estabelece e favorece a maior dissecação exibe suma importância.

\section{Considerações finais}

A característica marcante na morfologia das escarpas é a presença de vales suspensos de diferentes dimensões espaciais. Associados a esses vales encontram-se knickpoints e inflexões bruscas de canal, bem como vales aluviais na bacia adjacente em cabeceiras de drenagem de dimensões desproporcionais para o contexto geomorfológico atual em bordas de escarpa. Tais elementos apontam para cenário regional generalizado de capturas fluviais nas bordas das escarpas. Os vales suspensos também se apresentam como registro morfológico do avanço da rede hidrográfica sobre as bordas escarpadas.

Nas diferentes áreas mapeadas, relevo e drenagem apresentam-se orientados segundo direções bem marcadas que coincidem com estruturas de mapeamentos geológicos. Essas por vezes assumem direções discordantes quando comparadas com a direção principal regional NE-SW. Tal fato evidencia controle estrutural, em escala local, que pode se sobrepor ao regional na organização geomorfológica.

A dimensão dos vales suspensos indica estar relacionada à orientação dos canais na borda das escarpas que, em última análise, estão organizados segundo controles estruturais locais. Os maiores vales tendem a apresentar drenagens perpendiculares ao avanço dos fluxos sobre a escarpa. Tal organização facilita a ocorrência de capturas em ponto de elevada ordem ao longo dos canais o que submete esses a novo nível de base e facilita sua dissecação. Vales suspensos de pequena dimensão podem estar relacionados à interceptação da drenagem em ponto de pequena ordem hierárquica ou ao seccionamento do canal fluvial no mesmo sentido do fluxo remontante.

Por fim, as análises dos dados obtidos nesse trabalho assinalam para um quadro geral de condicionamento estrutural que comanda a organização geomorfológica e a evolução do relevo da área de estudo. Esse controle estrutural e sua direção assumem papel de destaque permitindo maiores ou menores capturas fluviais segundo sua organização. Nesse processo, o avanço dos cursos d'água sobre bacias hidrográficas situadas em degraus topográficos altimetricamente mais elevados tem a capacidade de impor uma reorganização da paisagem, produzindo novo cenário na nova superfície anexada. 


\section{Referências bibliográficas}

ALKMIM, F.F. (2004) O que faz de um cráton um cráton? O Cráton do São Francisco e as suas revelações Almeidianas ao delimitá-Io. In: MANTESSO-NETO, V.; BARTORELLI, A.; CARNEIRO, C.D.R.; BRITO-NEVES, B.B. Geologia do Continente Sul-Americano: evolução da obra de Fernando Flávio Marques de Almeida. São Paulo: Beca, p. 17-35.

AVELAR, A.S.; COELHO NETTO, A.L. (1992) Fraturas e desenvolvimento de unidades Geomorfológicas côncavas no médio vale do rio Paraíba do Sul. Revista Brasileira de Geociências, n. 2, p. 222-227.

BISHOP, P. (1995) Drainage rearrangement by river capture, beheading and diversion. Progress in Physical Geography, $\mathrm{n}$. 4, p. 449-473.

BRANDALISE, L. A. (1991) Programa de Levantamentos Geológicos Básicos do Brasil. Folha Barbacena - texto explicativo. Escala 1:100.000. Org. BRANDALISE, L. A. Brasília: DNPM-CPRM. 162 p.

BRANDALISE, L. A.; VIANA, H, S. (1993) Programa de Levantamentos Geológicos Básicos do Brasil. Folha Rio Pomba texto explicativo. Escala 1:100.000. Org. BRANDALISE, L. A.; VIANA, H, S. Brasília: DNPM-CPRM. 176 p.

BURBANK, D.W.; ANDERSON, R.S. (2001) Tectonic Geomorphology. Massachusetts: Blackwell Science Ltd. 274 p.

CHEREM, L.F.S.; VARAJÃO, C.A.C.; BRAUCHER, R.; BOURLĖS, D.; SALGADO, A.A.R.; VARAJÃO, A.C. (2012) Long-term evolution of denudational escarpments in southeastern Brazil. Geomorphology, n. 173, p. 118-127.

CHEREM, L.F.S.; VARAJÃO, C.A.C.; BRAUCHER, R.; BOURLÈS, D.; SALGADO, A.A.R.; VARAJÃO, A.C. (2013) 0 papel das capturas fluviais na morfodinâmica das bordas interplanálticas do sudeste do Brasil. Revista Brasileira de Geomorfologia, n. 4, p. 299-308.

COELHO NETTO, A.L. (2003) Evolução de cabeceiras de drenagem no médio vale do rio Paraíba do Sul (SP/RJ): a formação e o crescimento da rede de canais sob controle estrutural. Revista Brasileira de Geomorfologia, n. 2, p. 69-100. GONTIJO, A.H.F. (1999) Morfotectônica do médio vale do rio Paraíba do Sul: região da serra da Bocaina, estados de São Paulo e Rio de Janeiro. 1999. 259 f. Tese (Doutorado) - Instituto de Geociências e Ciências Exatas, Universidade estadual Paulista, Rio Claro.

GUNNELL, Y.; HARBOR, D.J. (2010) Butte detachment: how pre-rift geological structure and drainage integration drive escarpment evolution at rifted continental margins. Earth Surface Processes and Landforms, 35, p. 1373-1385.

HOWARD, A. D. (1967) Drainage analysis in geologic interpretation a summation. The American Association of Petroleum Geologists Bulletin, v. 51, n. 11, p. 2246-2259.

IBGE - Instituto de Geografia e Estatística. (2004) Vocabulário Básico de Recursos Naturais e Meio Ambiente. Coordenação de Recursos Naturais e Estudos Ambientais. $2^{\text {a }}$ Ed. Rio de Janeiro: IBGE. 330 p.

MARENT, B.R.; VALADÃO, R.C. (2015) Compartimentação geomorfológica dos planaltos escalonados do sudeste de Minas Gerais - Brasil. Revista Brasileira de Geomorfologia, n. 2, p. 255-270.

MODENESI-GAUTTIERI, M.C.; HIRUMA, S.T.; RICCOMINI, C. (2002) Morphotectonics of a high plateau on the northwestern flank of the Continental Rift of southeastern Brazil. Geomorphology, 43, p. 257-271.

NOCE, C.M.; ROMANO, A.W.; PINHEIRO, C.M.; MOL, V.S.; SOARES, A.C.P. (2003) Geologia das Folhas Ubá e Muriaé. In: PEDROSA-SOARES, A. C.; NOCE, C.M.; TROUW, R. A. J.; HEILBRON, M. Geologia e recursos minerais do sudeste mineiro: Volume III. Projeto Sul de Minas-Etapa I (COMIG-UFMG-UFRJ-UERJ), COMIG, p. 623-659.

OLLIER, C. The evolution of mountains on passive continental margins. (2004) In: OWENS, P.N.; SLAYMAKER, O. (Eds). Mountain Geomorphology. London: Edward Anold (Publishers) Ltd.

PRINCE, P.S.; SPOTILA, J.A.; HENIKA, W.S. (2010) New physical evidence of the role of stream capture in active retreat of the Blue Ridge escarpment, southern Appalachians. Geomorphology, 123, p. 305-319.

SALGADO, A.A.R.; SOBRINHO, L.C.G.; CHEREM, L.F.S.; VARAJÃO, C.A.C.; BOURLÈS, D.; BRAUCHER, R.; MARENT, B.R. (2012) Estudo da evolução da escarpa entre as bacias do Doce/Paraná em Minas Gerais através da quantificação das taxas de desnudação. Revista Brasileira de Geomorfologia, n.2, p. 213-222.

SILVA, L.G.E.; DANTAS, M.E.; COELHO NETTO, A.L. (1993) Condicionantes lito-estruturais na formação de níveis de base locais (knickpoints) e as implicações geomorfológicas no médio vale do rio Paraíba do Sul (RJ/SP). In: SIMPÓSIO DE GEOLOGIA DO SUDESTE, 3., 1993, Rio de Janeiro. Anais..., Rio de janeiro: SBG. p. 96-101.

SILVA, T.M.; MONTEIRO, H.S.; CRUZ, M.A.; MOURA, J.R.S. (2006) Anomalias de drenagem e evolução da paisagem no médio vale do rio Paraíba do Sul (RJ/SP). Anuário do Instituto de Geociências, n. 2, p. 210-224. 